\title{
Some Observations on Monetary Policy
}

IN RECENT YEARS I have become more perplexed and more skeptical about the use of monetary policy as a tool for very short-run stabilization. At present the profession has one body of analysis that relies upon an elaborated Keynesian approach to outline the link between changes in monetary policy and changes in real economic activity. This linkage runs from open market operations to bank reserves and then through the money supply and other factors to short-term interest rates. Movements in shortterm rates are translated into changes in long-term rates through a variety of channels. Long-term rates in turn provide the link to business investment, the stock market, consumption, and homebuilding.

This process has been described in great detail in models such as the FRB-MIT-Penn model. But one must qualify the results of these models by noting that the lags are very long and that many of the features of the outcome are very uncertain. The estimates of the response elasticities are subject to a wide range of disagreement. Some of the links, such as those involving the stock market, involve a great deal of uncertainty and possible interaction with other factors. These models do not lend much appeal to the notion of using monetary policy for precise short-run guidance.

An alternative approach attempts to go directly from some monetary aggregate to economic activity, without specifying the details of the linkages. This approach has been illustrated in many papers in recent years. While the results are consistent with those of the structural models in a general sense, I am skeptical about the more detailed implications. In par- 
ticular, it is difficult to understand why a substantial portion of the impact of monetary policy should be reflected in consumer services, as this approach turns out to imply. Such models are rather weak reeds to lean on in the conduct of monetary policy.

I conclude that ambitious goals for achieving short-run stabilization with monetary policy cannot be met. Instead, more emphasis should be placed on avoiding the extremes. In that context, an approach that relies on the monetary aggregates can best be justified, when applied with some caution, as a type of automatic stabilizer. If one is concerned about the economy running away in either direction, upper and lower limits on monetary growth-but not too firm limits-provide some automatic defense against other forces that might push the economy either strongly upward or strongly downward.

\section{The Recent Conduct of Policy}

Drawing on these observations about the general role of monetary policy, I shall outline my interpretation of the way in which monetary policy has been conducted recently in terms of open market operations. I shall then offer some tentative suggestions for a slightly better method of conducting policy, and finally, I shall apply those remarks to the current situation.

From my reading and conversations about the conduct of monetary policy in the past two or three years, my impression is that the Federal Reserve begins policy planning each period with an attitude of wanting to be restrictive-or expansionary, as the case may be-to a certain degree. The currently available statistics on monetary aggregates and interest rates are evaluated and interpreted relative to this general attitude. Second, in each period the policy makers study a staff projection reflecting a moneydemand function that relates the prospective growth of money for the weeks ahead to alternative levels of some interest rate in the money market.

A choice has to be made of the target rate of increase in the monetary aggregate for the next short period. My impression is that the baseline figure has been about 6 percent annual growth, if the monetary aggregate is interpreted as the narrowly defined money supply $\left(\mathrm{M}_{1}\right)$. If the staff projection implies that a change in interest rates would be required to hold that growth close to 6 percent, the Federal Open Market Committee makes a 
judgment that is related to its desire to be either restrictive or expansionary. If the mood is expansionary, the FOMC will resist any tendencies for interest rates to rise by letting money grow faster. If it is restrictive, it will let interest rates go up in order to stay close to the baseline growth rate for the monetary aggregate. How much of an interest rate rise it will accept depends partly on how much of a shift is implied by the staff forecast and partly on how restrictive it desires to be.

A second type of decision is required when the trading desk encounters a shift in the relationship between interest rates and the monetary aggregate that was not anticipated by the staff projection. A new, very short-run, decision may be made; again, that involves a compromise. If the surprise is on the up side, the choice is between letting the aggregates get bigger than the FOMC had initially intended and letting rates go higher.

This policy-making process can produce peculiar results. In some periods when policy is meant to be restrictive, the monetary aggregate may grow rapidly. That is an understandable outcome, stemming from substantial upward shifts in the demand function for money and a consequent compromise between raising interest rates sharply and permitting rapid monetary growth. But more paradoxical results emerge when shifts in the demand for money are opposite in direction to the thrust of the general cyclical movement of the economy. For example, the demand for money sometimes shifts down in the short run when the economy is expanding rapidly and the FOMC is trying to be restrictive. The committee must then compromise. If it holds the growth aggregates up, it must let interest rates fall-in spite of its desire to be restrictive. To avoid a drop in interest rates, it would have to accept very low rates of growth in the aggregates. A strange timing of changes in open market policy has occasionally resulted from the compromise actually adopted in the face of this type of conflict. In the fall of 1972, for example, a policy based on interest rates might have resulted in an earlier upturn in rates and a smaller growth in the monetary aggregates than in fact took place. But the devotion to the aggregates in those peculiar circumstances delayed the application of real restraint. Even if one wishes to place some weight on the monetary aggregates, I cannot see the sense of putting such great emphasis on very short-run month-tomonth movements as to push policy in a direction contrary to the basic objective-such as letting interest rates fall when the intention is to be restrictive. 


\section{An Alternative Approach}

I suggest a somewhat different method of making the compromise between aggregates and interest rates. Consider monetary policy decisions in three possible states of the economy. One is a state in which there is little concern that the economy will run away in either direction. In that state, a forecast of activity based on a continuation of current interest rates would not be sharply different from a reasonable target growth path, and would not reveal strong cumulative forces that could take hold in either direction. I would opt in this case essentially for an interest rate approach to monetary policy - that is, let the monetary aggregates fall where they may in response to wiggles and jiggles in the demand for money.

The second state is one in which excessive growth in demand is a serious threat. Such a case of possible boom poses a greater need for a policy that will provide some automatic stabilization against upward thrusts in demand and less concern about a rather sudden upward jolt in interest rates. Here some ceiling rate of growth for the monetary aggregates might be one desirable element of policy in an effort to contain the economy. If, however, a boom has really started, such a governor may not supply enough restraint. To provide a further stopper, it may be desirable to produce a rather sudden jump in interest rates-say, by a major rise in the discount rate reinforced by an upward push on the federal funds rate. Once that rate movement is accomplished, the strategy based on ceiling growth of monetary aggregates would be applied.

The third state, in which the major concern is a recession, is the opposite of the second. Some minimum growth rate of money can be a useful automatic stabilizer to bolster demand. If the situation is very serious, it would be appropriate to reduce interest rates to a lower level rather suddenly and then adopt a floor on the rate of growth of the money supply or some other monetary aggregate.

In summary, a floor or ceiling growth rate for the monetary aggregate is a reasonable approach when the risks are one-sided and compelling evidence exists for monetary policy to be either expansionary or restrictive. But in the mid-range of the first state, a devotion to short-term stability in the monetary aggregates can lead to frequent and unjustified reversals of open market policy. 


\section{The Current Situation}

I would place the current economic situation in the first class of cases. The United States is no longer in the second state: there is little prospect that the economy will renew its spurt. Nor is it in the third state, in which a weak outlook would call for drastic policy changes. Most forecasters see a "welcome slowdown" with real growth close to 4 percent for the latter half of 1973, graduating down to lower figures in the first half of 1974. Beyond that, the picture is less clear, but some foresee an improvement later in the year. Thus, the profession is projecting growth rates below the rate of expansion of potential output, but still positive. These forecasts assume some easing of monetary policy, and a moderate rise in government expenditures. The strength comes from plant and equipment and inventory investment, while the weakness lies in homebuilding and a projected rise in personal saving rates. As always, these forecasts are subject to major errors, but, at present, the uncertainties look fairly symmetrical to me.

In this situation the correct posture for monetary policy will depend a good deal on the policy maker's attitude toward taking risks on inflation versus taking risks on unemployment. On the inflation side, increased slack of labor markets and falling corporate profits should provide restraint against any large acceleration of wage settlements in the face of strong and inevitable cost-push forces generated by the recent jump in the cost of living. Some decline in the prices of nonfood raw materials can be anticipated as a result of the slowdown. Thus, the standard forecast projects modest improvement rather than continued deterioration in the performance of prices. A major upside surprise in real growth could jeopardize that improvement, while a major downside surprise would involve a high cost to get a little more relief from inflation. My interpretation is that this outlook does not justify an attempt to conduct policy so as to create a new and substantially lower or higher path of aggregate demand. Rather, it calls for a policy strategy to help validate the forecasts, preserving the flexibility to jump either way in the event of major unanticipated developments.

Since I do not see an explosive situation or key role for automatic stabilization, I would focus on interest rates. I would aim at a gradual decline in the federal funds rate, perhaps starting to drop it 50 basis points per month and planning for a somewhat more rapid drop after a while unless contrary signals develop. I would ignore short-run gyrations in the monetary ag- 
gregates and aim at 6 percent as a tentative target for short-term interest rates early in the spring of 1974 .

\section{Discussion}

SEVERAL OF THE participants commented on the choice of interest rates versus monetary aggregates as the proximate target of monetary policy. William Poole disagreed with Duesenberry about the risks of a policy oriented toward interest rates in the months ahead; he felt that such a policy might bring interest rates down less rapidly than one conducted by an aggregate target if, in fact, the economy should soften significantly and fairly prompt reductions in interest rates became appropriate. On the other hand, if the demand for money should be surprisingly intense for a while, Duesenberry's proposal of a gradual reduction in interest rates could generate very rapid monetary growth, and Poole suspected that that might generate a political backlash toward much tighter money thereafter. Because the growth of the money stock had exceeded the intentions and expectations of the policy makers during the spring, he felt there would not be much tolerance for rapid money growth in the near future.

William Gibson echoed Poole's concerns about policies oriented toward interest rates. He suggested that Duesenberry's own desired minimization of destabilizing monetary policy stances would be more likely to be achieved through a policy of maintaining moderate growth in the monetary aggregates. Barry Bosworth felt, on the other hand, that the monetary aggregates should be used only as short-run indicators, primarily as additional evidence on the nature and significance of changes in economic activity. He stressed that, over the longer run, the policy maker should be focusing on changes in GNP, prices, and employment, rather than on any of the instruments of policy. He noted that exclusive concern with interest rates would not take account of the impact of changes in financial policies affecting mortgages, and that these could have a major effect in either reinforcing or offsetting the actions of the Federal Reserve.

A number of participants emphasized the prospect of a sizable decline in homebuilding during the coming year, possibly large enough to swamp prospective real gains in plant and equipment spending and in inventory investment. Murray Weidenbaum felt that homebuilding is currently being 
cushioned by the previous commitments of mortgage lenders contracted before interest rates rose so sharply. Hence, the severity of the homebuilding decline can probably be gauged accurately only when the backlog of such commitments runs out, as it will in a few months.

Charles Holt questioned the completeness of Duesenberry's three-state model of monetary policy. Duesenberry agreed that the world had more continuity than that categorization implied; he noted that he had actually designated five different states, including his stopper on both the restrictive and expansionary sides.

Lawrence Klein pointed out that, while real growth has not deviated significantly from the rate predicted by most economists at the end of 1972, the inflation rate has vastly exceeded predictions. He raised the question of how both the targets for economic activity and the instruments of monetary policy should be adjusted when such a surprise is revealed. Duesenberry felt that his proposed ceiling growth rate on money might help under those circumstances. But he stressed that, in his judgment, the unique kind of inflation experienced in 1973 would not justify a significant lowering of targets for real economic activity. Joseph Pechman noted that, nonetheless, Duesenberry's own strategy essentially accepted a fairly significant rise in unemployment to rates higher than anyone would previously have espoused as a norm for prosperity. 